\title{
HUBUNGAN KARAKTERISTIK ANAK DAN IBU DENGAN KEJADIAN TEMPER TANTRUM PADA ANAK USIA PRASEKOLAH
}

\author{
The Correlation Between Child and Mother's Characteristics with Incidence Of Temper \\ Tantrum in Preschool Aged Children
}

\author{
Diah Fauzia Zuhroh ${ }^{1}$, Kamilah ${ }^{2}$ \\ ${ }^{1,2}$ Program Studi Ilmu Keperawatan Universitas Muhammadiyah Gresik \\ Alamat Korespondensi : Prodi Ilmu Keperawatan dan Ners UMG \\ Jl. Proklamasi No. 54 Gresik, JawaTimur - Indonesia \\ E-mail: fauzia_diah@umg.ac.id
}

\begin{abstract}
ABSTRAK
Temper tantrum adalah suatu perilaku yang termasuk bagian dari perkembangan emosi anak. Perkembangan emosi anak erat kaitannya dengan kondisi lingkungan keluarga terutama orang tua. Tujuan penelitian untuk mengetahui hubungan karakteristik anak dan ibu dengan kejadian temper tantrum pada anak usia prasekolah di Bangkalan.

Janis penelitian analitik pendekatan cross sectional. Populasi sebanyak 38, dengan besar sampel 35 ibu dan anak yang diambil dengan teknik simple random sampling. Analisis data menggunakan uji contingency coefficient dan Fisher's exact test.

Karakteristik anak menunjukkan jenis kelamin sebagian besar laki-laki 57,1\%, umur ibu sebagian besar 17-25 tahun 54,3\% dan sebagian besar ibu tidak bekerja 51,4\%. Hasil uji contingency coefficient dari hubungan jenis kelamin anak dan kejadian temper tantrum diperoleh nilai $p=0,070$. Sementara dari hasil uji Fisher's exact test dari hubungan umur ibu dengan kejadian temper tantrum diperoleh nilai $\mathrm{p}=0,026$ dan pada hubungan pekerjaan ibu dengan kejadian temper tantrum diperoleh nilai $\mathrm{p}=0,013$.

Hasil penelitian ada hubungan pola asuh orang tua dengan kejadian temper tantrum pada anak usia prasekolah di Bangkalan.
\end{abstract}

Kata kunci : ibu, temper tantrum, usia prasekolah

ABSTRACT
Temper tantrum is a behavior includes the part of the child's emotional development. The development of the child's emotions are closely related to environmental conditions of families especially parents. The purpose of the study to find out the characteristics of the child and the mother's relationship with his temper tantrum in preschool-aged children in the village of Planggiran Tanjung Bumi Bangkalan.

Analytic using a cross sectional design. Entire population of preschool age children and mother as many as 38, and a sample of as much as 35 mothers and children taken with simple random sampling technique. Data analysis using the test's and Fisher's exact contingency test.

Characteristics of children based on gender are predominantly male (57.1\%) While for the characteristics of the mother based on age of majority age of 17-25 years (54.3\%) and based on the work of the majority of mothers do not work (51.4). Test results of the relationship's contingency gender and Genesis temper tantrum earned value $p=0,070$. While Fisher's exact test results from a test of the relationship age mom with Genesis temper tantrum earned value $p=0,026$ and on the relationship of work mother with Genesis temper tantrum dieproleh value $p=0,013$.

There is a connection parenting parents with his temper tantrum in preschool-aged children in the village of Planggiran Tanjung Bumi Bangkalan.

Keywords: preschool age, mother, temper tantrum 


\section{PENDAHULUAN}

Temper tantrum pada umumnya terjadi pada hampir seluruh periode masa kanak-kanak termasuk anak prasekolah yang berusia antara 3-6 tahun. Temper tantrum merupakan suatu perilaku yang masih termasuk bagian dari proses perkembagan emosi. Anak dengan temper tantrum memiliki kelemahan dalam mengendalikan emosinya, saat marah anak bisa menangis dengan menjerit, berteriak, membuang barang, berguling-guling di lantai, menghentakkan kaki, sampai membenturkan kepala. Perkembangan emosi anak erat kaitannya dengan kondisi lingkungan keluarga terutama orang tua. Sebab apapun tindakan yang dilakukan oleh orang tua sangat berperan dalam setiap tahap perkembangan anak.

Semua orang tua mengharapkan anaknya kelak tumbuh menjadi manusia yang cerdas, bahagia, dan memiliki kepribadian yang baik. Orang tua dituntut untuk dapat mengamati perkembangan anak dengan baik dan menerapkan pola asuh yang tepat untuk mewujudkan harapan tersebut.

Orang tua terdiri dari ayah dan ibu, meskipun ayah dan ibu mempunyai peran yang sama pentingnya dalam mendidik anak, namun ibu mempunyai ikatan yang kuat dengan anak sejak dalam kandungan dan terus berkembang setelah anak dilahirkan selama ibu menjadi pengasuh utama. Kualitas dan kuantitas hubungan dengan orang terdekat atau orang tua memainkan peran penting dalam perkembangan terutama dalam perkembangan emosi, intelektual, dan kepribadian anak.

Penelitian tentang perilaku anak oleh Wakschlag dan timnya (2012) yang dikutip oleh Wiyouf (2017) pada 1.500 orang tua yang memiliki anak usia 3-5 tahun mayoritas balita $83,7 \%$ terkadang mengalami temper tentrum, $8,6 \%$ yang setiap hari marah dan mengamuk. Sedangkan di Indonesia, menurut Kompas (2012) yang dikutip oleh Wiyouf (2017) balita yang biasanya mengalami tantrum dalam waktu satu tahun, $23-83 \%$ dari anak usia 2-4 tahun pernah mengalami temper tantrum.

$$
\text { Penelitian oleh Dinantia (2014) }
$$

tentang hubungan pola asuh orang tua dengan frekuensi dan intensitas perilaku temper tantrum pada anak usia toddler di Kelurahan Suka Maju, Kecamatan Sail, Kota Pekanbaru, didapatkan $7(77,8 \%)$ dari $9(100 \%)$ responden yang menerapkan pola asuh otoriter perilaku temper tantrum anaknya dikategorikan parah dan 3 (100\%) responden yang menerapkan pola asuh permisif perilaku temper tantrum anaknya dikategorikan parah. Sementara responden yang menerapkan pola asuh demokrasi perilaku temper tantrum anaknya di kategorikan parah hanya $33(45,8 \%)$ dari 72 $(100 \%$.)

Studi penduhuluan yang dilakukan di PAUD Cut Nya' Dien Desa Planggiran Tanjung Bumi Bangkalan. Berdasarkan hasil kuesioner pada 10 ibu yang memiliki anak berusia 3-6 tahun, 90\% diantaranya sering mengalami tindakan-tindakan yang mengarah pada temper tantrum seperti menangis dengan menjerit-jerit atau menangis dengan keras sebanyak $30 \%$ anak, memukul dan menendang-nendang barang atau orang lain sebanyak $20 \%$ anak, melemparkan barang dan berguling-guling di lantai saat sedang marah sebanyak 40\% anak. Dari 10 ibu yang diwawancarai mengenai pola asuh yang 
diterapkan dalam keluarga, 80\% ibu cenderung menerapkan pola asuh otoriter dan $20 \%$ ibu cenderung menerapkan pola asuh pemanja.

Tantrum pada anak bisa muncul karena beberapa faktor, antara lain: faktor fisiologis, yaitu karena anak merasa lelah, lapar atau sakit; faktor psikologis, antara lain anak mengalami kegagalan, dan orang tua yang terlalu menuntut anak sesuai harapan orang tua; faktor orang tua, yakni pola asuh dan komunikasi; dan faktor lingkungan, yaitu lingkungan keluarga dan lingkungan luar rumah (Wiyouf, 2017). Tantrum biasanya terjadi karena anak mengalami depresi, kesedihan yang mendalam, dan stress. Anak tidak tahu bagaimana cara mengekspresikan emosi tersebut sehingga menyebabkan anak frustrasi dan dikeluarkan dalam bentuk tingkah laku tantrum.

Temper tantrum juga dapat terjadi karena rasa marah yang tertahan pada orang tua karena anak merasa kurang kasih sayang dan perhatian dari orang tua. Saat hal ini terjadi terus menerus pada akhirnya anak akan merasa tertekan dan hal ini dapat memicu sikap anak menjadi emosional dan mengungkapkan dengan perilaku temper tantrum (Sriyanti, 2014).

Beberapa pendekatan yang dilakukan untuk mengurangi perilaku temper tantrum antaranya dengan mengubah pola asuh orang tua. Orang tua diharapkan dapat menghormati kebutuhan dan pendapat anak, tetapi orang tua tetap menetapkan batasan tegas yang tepat. Selain itu juga dibutuhkan adanya pola komunikasi yang efektif dalam keluarga. Baiknya kualitas komunikasi dalam keluarga akan berdampak baik bagi keutuhan dan keharmonisan dalam keluarga itu sendiri serta berdampak baik terhadap perkembangan emosional anak.

Bermain mempunyai arti penting dalam kehidupan anak. Oleh karena itu, bermain juga dapat diterapkan sebagai strategi dalam mengurangi perilaku temper tantrum pada anak, salah satunya yaitu permainan kooperatif seperti menyusun huruf bersama dan tebak gerakan. Anak dalam permainan kooperatif dapat melakukan kerja sama antara anak-anak yang terlibat sehingga mengurangi egosentris dan reaksi agregasi yang biasa ditunjukan oleh anak dengan temper tantrum.

\section{METODE}

Penelitian analitik korelasi dengan pendekatan cross sectional. Populasi Populasi seluruh ibu dan anak usia prasekolah sebanyak 38 orang. Besar Sampel 35 anak menggunakan teknik simple random sampling. Penelitian ini dilakukan di PAUD Cut Nya' Dien dan TK Baitur Rohim Desa Planggiran Kecamatan Tanjung Bumi Kabupaten Bangkalan.

\section{HASIL DAN PEMBAHASAN \\ Umur Anak}

Tabel 1. Distribusi Frekuensi Umur Anak di Bangkalan 2019

\begin{tabular}{lcc}
\hline Umur anak & Frekuensi & Persentase \\
\hline 3 tahun & 2 & 5,7 \\
4 tahun & 10 & 28,6 \\
5 tahun & 15 & 42,9 \\
6 tahun & 8 & 22,9 \\
\hline Total & $\mathbf{3 5}$ & $\mathbf{1 0 0}$ \\
\hline
\end{tabular}

Sumber: Data Primer Peneliti, Tahun 2019

Berdasarkan tabel 1 diperoleh bahwa hampir setengahnya umur anak yaitu usia 5 tahun sebanyak 15 orang $(42,9 \%)$ di Bangkalan. 


\section{Jenis Kelamin Anak}

Tabel 2. Distribusi Frekuensi Jenis Kelamin Anak di Bangkalan 2019

\begin{tabular}{lrr}
\hline $\begin{array}{l}\text { Jenis } \\
\text { kelamin } \\
\text { anak }\end{array}$ & Frekuensi & Persentase \\
\hline Laki-laki & 20 & 57,1 \\
Perempuan & 15 & 42,9 \\
\hline Total & $\mathbf{3 5}$ & $\mathbf{1 0 0}$
\end{tabular}

Sumber: Data Primer Peneliti, Tahun 2019

Sebagian besar jenis kelamin anak adalah laki-laki yaitu sebanyak 20 orang $(57,1 \%)$ di Bangkalan. Perbedaan jenis kelamin merupakan awal dari perbedaan fisik dan perilaku antara laki-laki dan perempuan.

Secara fisik, anak laki-laki cenderung lebih tinggi tingkat aktifitasnya dibandingkan anak perempuan. Penampilan motorik juga lebih baik terutama setelah anak memasuki masa pubertas. Menurut Gelombok (2008) dalam Desiningrum (2012) tipe pilihan berdasarkan jenis kelamin meningkat pada saat anak memasuki usia toddler dan masa pertengahan anak-anak. Tingkat perilaku yang ditunjukkan pada dasar perbedaan jenis kelamin diawal kehidupan merupakan indikator yang kuat dalam perilakunya berdasarkan jenis kelamin di masa mendatang.

Umur Ibu

Tabel 3. Distribusi Frekuensi Umur Ibu di Bangkalan 2019

\begin{tabular}{lcc}
\hline Umur ibu & Frekuensi & Persentase \\
\hline 17-25 Tahun & 19 & 54,3 \\
26-45 Tahun & 16 & 45,7 \\
\hline Total & $\mathbf{3 5}$ & $\mathbf{1 0 0}$ \\
\hline
\end{tabular}

Sumber: Data Primer Peneliti, Tahun 2019

Sebagian besar ibu berumur 17-25 tahun yaitu sebanyak 19 orang $(54,3 \%)$ di PAUD Cut Nya' Dien dan TK Baitur Rohim
Desa Planggiran Kecamatan Tanjung Bumi Kabupaten Bangkalan. Usia ibu dapat menjadi indikator dalam kesiapan menajadi orang tua, karena peran ibu akan berjalan dengan baik jika ibu berada pada rentang usia yang dewasa. Semakin cukup umur ibu maka tingkat kematangan akan lebih dalam berfikir dan pengambilan keputusan. Menurut Wong (2008) dalam Lusiana (2015) menyatakan bahwa kesiapan orang tua dalam menjalankan pola pengasuhan dapat dilakukan dengan pendidikan yang baik, selain itu rentang usia orang tua terlalu muda atau muda maka tidak dapat menjalankan peran tersebut secara optimal karena diperlukan kekuatan fisik dan psikologis (Lusiana, 2012).

\section{Pekerjaan Ibu}

Tabel 4 Distribusi Frekuensi Pekerjaan Ibu di Bangkalan 2019

\begin{tabular}{lrr}
\hline Pekerjaan & Frekuensi & Persentase \\
\hline Bekerja & 17 & 48,6 \\
Tidak bekerja & 18 & 51,4 \\
\hline \multicolumn{1}{c}{ Total } & $\mathbf{3 5}$ & $\mathbf{1 0 0}$ \\
\hline
\end{tabular}

Sumber: Data Primer Peneliti, Tahun 2019

Hampir setengahnya ibu bekerja yaitu sebanyak 17 orang $(48,6 \%)$ di PAUD Cut Nya' Dien dan TK Baitur Rohim Desa Planggiran Kecamatan Tanjung Bumi Kabupaten Bangkalan. Peran ibu yang awalnya adalah sebagai istri, ibu dari anakanaknya, mengurus rumah tangga, sebagai pengasuh, pendidik anak-anaknya, saat ini mulai berubah. Banyak ibu telah berperan sebagai pencari nafkah tambahan bagi keluarganya. Ibu yang sibuk bekerja atau berkarir dapat mengakibatkan perhatian terhadap keluarga termasuk anak menjadi berkurang, bahkan tidak sedikit yang akhirnya 
tidak memperhatikan kondisi anak Gunarsa (2008) dalam Imaniyah (2013).

Kejadian Temper Tantrum pada Anak

Tabel 5. Distribusi Frekuensi Kejadian Temper Tantrum di Bangkalan 2019

\begin{tabular}{llr}
\hline $\begin{array}{l}\text { Kejadian Temper } \\
\text { Tantrum }\end{array}$ & $\begin{array}{l}\text { Frekuen } \\
\text { si }\end{array}$ & Persentase \\
\hline Terjadi & 30 & 85,7 \\
Tidak terjadi & 5 & 14,3 \\
\hline Total & $\mathbf{3 5}$ & $\mathbf{1 0 0}$ \\
\hline
\end{tabular}

Sumber: Data Primer Peneliti, Tahun 2019

Hampir seluruh anak mengalami perilaku temper tantrum yaitu sebanyak 30 orang $(85,7 \%)$. Awalnya anak melakukan tantrum untuk berkomunikasi dengan orang tua atau pengasuh. Anak ingin orangtua tahu bahwa mereka lapar, sakit, atau mengantuk. Ketika anak mulai bisa bicara mereka akan mengeluarkan perasaannya dengan kata-kata, namun ketika stress anak kehilangan kata-kata dan kembali melakukan tantrum. Alasan kedua anak melakukan tantrum adalah untuk melawan kontrol dari orang tua yaitu untuk memperoleh keinginannya. Alasan ketiga adalah untuk melampiaskan energi emosionalnya. Emosi menyebabkan reaksi fisik pada tubuh anak tidak dapat ditahan sehinggga terjadi ledakan emosi (temper tantrum).

Menurut Hurlock (2010) yang dikutip oleh Kirana (2013) situasi yang menimbulkan temper tantrum antara lain; (1) Rintangan terhadap gerak yang diinginkan anak, baik rintangan itu berasal dari orang lain atau dari ketidakmampuan diri sendiri, (2) Rintangan terhadap aktivitas yang sudah mulain berjalan, (3) Rintangan terhadap keinginan, rencana, dan niat yang ingin dilakukan anak.
Pada data didapatkan bahwa sebagian kecil 5 anak (14,3\%) tidak mengalami perilaku temper tantrum. Temper tantrum merupakan sebuah pola perilaku interaktif bukan sekedar reaktif, sehingga anak-anak ketika melakukan tantrum, hampir sebagian besar terjadi saat di tempat-tempat keramaian, atau setidaknya anak membutuhkan orang lain untuk menyaksikan perilaku tantrumnya. Sehingga saat sedang sendiri, walaupun anak dalam keadaan kesal atau marah, anak tidak akan melakukan tantrum.

Perkembangan emosi anak erat kaitannya dengan kondisi lingkungan keluarga terutama orang tua. Reaksi orangtua ketika menghadapi tantrum anak merupakan salah satu hal yang sangat berpengaruh terhadap kecenderungan anak untuk mengulangi perilaku tersebut. Jika orang tua memberikan pengaruh yang baik, maka akan berdampak baik pula bagi perkembangan dan pertumbuhan anak. Kemampuan anak mengatur emosi diri sendiri sangat bergantung pada kesadaran diri. Emosi dikatakan berhasil dikelola apabila anak mampu menghibur diri ketika sedih, mampu melepas kecemasan, kemurungan dan bangkit kembali dengan segera dari hal-hal tersebut. Hal ini sejalan dengan pendapat para ahli dalam Astuti (2016) bahwa Tantrum pada anak usia dini biasanya mencapai puncaknya pada usia 1 hingga 3 tahun dan akan menghilang secara bertahap seiring bertambahnya usia anak dan kemampuan mengungkapkan emosi dalam dirinya. 
Hubungan Jenis Kelamin Anak dengan Kejadian Temper Tantrum pada Anak Usia Prasekolah Tabel 6 Hubungan Jenis Kelamin Anak dengan Kejadian Temper Tantrum pada Anak Usia Prasekolah di Bangkalan 2019

\begin{tabular}{lccccccc}
\hline & \multicolumn{3}{c}{$\begin{array}{c}\text { Kejadian temper tantrum pada } \\
\text { anak usia prasekolah }\end{array}$} & \multicolumn{2}{c}{ Jumlah } \\
\cline { 2 - 7 } Jenis Kelamin Anak & \multicolumn{2}{c}{ Terjadi } & Tidak terjadi & \multicolumn{2}{c}{ Total } \\
\cline { 2 - 8 } & $\mathbf{F}$ & $\mathbf{\%}$ & $\mathbf{F}$ & $\mathbf{\%}$ & $\mathbf{F}$ & $\%$ \\
\hline Laki-laki & 19 & 95,0 & 1 & 5,0 & 20 & 100 \\
Perempuan & 11 & 73,3 & 4 & 26,7 & 15 & 100 \\
Total & 30 & 85,7 & 5 & 14,3 & 35 & 100 \\
\hline
\end{tabular}

Sumber: Data Primer Peneliti, Tahun 2019

Berdasarkan data bahwa pada anak dengan jenis kelamin laki-laki hampir seluruhnya $(95,0 \%)$ mengalami perilaku temper tantrum dan sebagian kecil $(5,0 \%)$ tidak mengalami perilaku temper tantrum. Sementara pada anak dengan jenis kelamin perempuan sebagian besar $(73,3 \%)$ mengalami perilaku temper tantrum dan hampir setengahnya $(26,7 \%)$ tidak mengalami perilaku temper tantrum. Hasil analisis dengan menggunakan uji contingency coefficient didapatkan nilai $\mathrm{p}=0,070<0,05$. Ada hubungan jenis kelamin anak dengan kejadian temper tantrum dengan kejadian temper tentrum pada anak usia prasekolah.

Jenis kelamin sangat berpengaryh terhadap kejadian temper tantrum, karena emosional anak laki-laki lebih tinggi daripada anak perempuan. Dilihat dari segi fisik, anak laki-laki cenderung lebih kuat dibandingkan anak perempuan, anak perempuan cenderung lebih bisa menahan emosi dari pada anak lakilaki. Anak perempuan juga lebih mandiri dibandingkan anak laki-laki.

$$
\text { Anak laki-laki cenderung }
$$
membutuhkan perhatian yang lebih banyak daripada anak perempuan untuk mencapai suatu kemandirian. Pernyataan tersebut dapat menunjukkan bahwa apabila seorang anak laki-laki dan perempuan diberikan perhatian yang sama belum tentu dapat mandiri karena itu anak laki-laki harus lebih banyak mendapat perhatian, karena anak laki-laki perkembangan otak anak laki-laki dibagian otak depan yang mengenali rangsangan-rangsangan penting untuk mengendalikan diri lebih lambat daripada anak perempuan Putri (2013) dalam Lusiana (2015).

\section{Hubungan Umur Ibu dengan Kejadian Temper Tantrum pada Anak Usia Prsekolah}

Tabel 7. Hubungan Umur Ibu dengan Kejadian Temper Tantrum pada Anak Usia Prasekolah Bangkalan Bulan 2019

\begin{tabular}{|c|c|c|c|c|c|c|}
\hline \multirow{3}{*}{ Umur Ibu } & \multicolumn{4}{|c|}{$\begin{array}{l}\text { Kejadian temper tantrum pada } \\
\text { anak usia prasekolah }\end{array}$} & \multirow{2}{*}{\multicolumn{2}{|c|}{$\begin{array}{l}\text { Jumlah } \\
\text { Total }\end{array}$}} \\
\hline & \multicolumn{2}{|c|}{ Terjadi } & \multicolumn{2}{|c|}{ Tidak terjadi } & & \\
\hline & $\mathbf{F}$ & $\%$ & $\mathbf{F}$ & $\%$ & $\mathbf{F}$ & $\%$ \\
\hline 17-25 tahun & 19 & 100 & 0 & 0 & 19 & 100 \\
\hline $26-45$ tahun & 11 & 68,8 & 3 & 31,2 & 16 & 100 \\
\hline Total & 30 & 85,7 & 5 & 14,3 & 35 & 100 \\
\hline
\end{tabular}

Sumber: Data Primer Peneliti, Tahun 2019 
Berdasarkan data diperoleh bahwa pada anak dengan umur ibu 17-25 tahun seluruhnya (100\%) mengalami perilaku temper tantrum. Sementara pada anak dengan umur ibu 26-45 tahun sebagian besar $(68,8 \%)$ mengalami perilaku temper tantrum dan hampir setengahnya $(31,2 \%)$ tidak mengalami perilaku temper tantrum. Hasil analisis dengan menggunakan uji Fisher's exact test didapatkan nilai $\mathrm{p}=0,013<0,05$. Ada hubungan umur ibu dengan kejadian temper tentrum pada anak usia prasekolah.

Usia ibu dapat menjadi indikator dalam kesiapan menajadi orang tua, karena peran ibu akan berjalan dengan baik jika ibu berada pada rentang usia yang dewasa. Semakin cukup umur ibu maka tingkat kematangan akan lebih dalam berfikir dan pengambilan keputusan.Seorang wanita dikatakan dewasa jika telah menginjak usia 21 tahun keatas. Kedewasaan ibu secara psikologis sangat berperan penting karena akan berpengaruh terhadap pola asuh anak, yaitu ibu lebih mampu berperan aktif dan mampu memberikan stimulus-stimulus kepada anak. peran aktif seorang ibu terhadap perkembangan anaknya sangat diperlukan terutama pada saat mereka masih balita untuk mengembangkan kemampuan dasar yang dimilikinya Verawati (2013) dalam Widyana (2015).

Menurut Wong (2008) dalam Lusiana (2015) menyatakan bahwa kesiapan orang tua dalam menjalankan pola pengasuhan dapat dilakukan dengan pendidikan yang baik, selain itu rentang usia orang tua terlalu muda atau muda maka tidak dapat menjalankan peran tersebut secara optimal karena diperlukan kekuatan fisik dan psikologis. Menurut Widyana (2015) pasangan usia dini berada pada rentang usia dibawah 21 tahun, yang mana pada saat ini belum dianggap matang secara psikologis maupun fisik. Pada usia dibawah 21 tahun seseorang memiliki emosional yang kurang stabil sehingga memiliki kemungkinan lebih besar untuk sulit mengendalikan diri dan menjalani kewajiban dalam dalam hidup berumah tangga dan mengasuh anak. tidak jarang ditemukan pada pasangan usia muda masih banyak bergantung pada orang tua yang menunjukkan bahwa tingkat kemandirian dan kesiapan masih kurang untuk menjalani peran dan kewajiban sebagai orang dewasa sehingga kurang memahami dalam mendidik ataupun mengasuh anak.

Usia 21 tahun keatas dikatakan telah memasuki masa dewasa dan telah dianggap memiliki kematangan baik dari fisik maupun psikologis. Pasangan usia dewasa memiliki kematangan emosional yang lebih stabil dibandingkan pasangan usia dini. Karena mereka memiliki pengalaman yang lebih banyak serta lebih lama bisa mempersiapkan diri untuk menjalani peran sesungguhnya pada masa dewasa salah satunya untuk menjalani peran dalam pengasuhan anak. kematangan psikologis pasangan usia dewasa akan membantu mengarahkan emosional anak dalam mengasuh anak, sehingga orang tua akan lebih mampu untuk mengontrol pola pengasuhan anak segingga akan terwujud kepribadian anak yang lebih baik.

Pola asuh orang tua merupakan salah satu hal yang sangat berperan penting dalam proses pertumbuhan dan perkembangan anak. 
Hal ini disebabkan karena berhasil atau gagalnya proses pembentukan kepribadian dan potensi anak kelak, bergantung pada bagaimana orangtua mengasuh dan mendidik anak, mengingat orang tua atau keluarga merupakan lembaga sosialisasi yang pertama dan utama bagi anak. Orang tua yang matang baik dari segi biologis maupun psikologis untuk menghadapi perannya, tentunya mempunyai pengetahuan dan kesadaran yang tinggi dalam memberikan pengasuhan yang baik bagi anak. Pola pengasuhan yang penuh kehangatan dan cinta kasih, tetapi pada saat yang bersamaan pula menciptakan sebuah struktur dan batas yang jelas merupakan hal yang penting untuk mengatasi anak yang berkeinginan kuat dan dapat mengurangi perilaku temper tantrum.

\section{Hubungan Pekerjaan Ibu dengan Kejadian Temper Tantrum pada Anak Usia Prasekolah}

Tabel 8 Hubungan Pekerjaan Ibu dengan Kejadian Temper Tantrum pada Anak Usia Prasekolah di Bangkalan 2019

\begin{tabular}{|c|c|c|c|c|c|c|}
\hline \multirow{3}{*}{ Pekerjaan Ibu } & \multicolumn{4}{|c|}{$\begin{array}{l}\text { Kejadian temper tantrum pada anak usia } \\
\text { prasekolah }\end{array}$} & \multicolumn{2}{|c|}{ Jumlah } \\
\hline & Terjadi & & ida & & & \\
\hline & $\mathbf{F}$ & $\%$ & $\mathbf{F}$ & $\%$ & $\mathbf{F}$ & $\%$ \\
\hline Bekerja & 17 & 100 & 0 & 0 & 17 & 100 \\
\hline Tidak bekerja & 13 & 72,2 & 5 & 27,8 & 18 & 100 \\
\hline Total & 30 & 85,7 & 5 & 14,3 & 35 & 100 \\
\hline
\end{tabular}

Sumber: Data Primer Peneliti, Tahun 2019

\section{Berdasarkan hasil analisis dengan} menggunakan uji Fisher's exact test didapatkan nilai $\mathrm{p}=0,026<0,05$ ada hubungan pekerjaan ibu dengan kejadian temper tentrum pada anak usia prasekolah. Berdasarkan data diperoleh bahwa pada anak dengan ibu bekerja seluruhnya $(100 \%)$ mengalami perilaku temper tantrum. Sementara anak dengan ibu yang tidak bekerja sebagian besar $(72,2 \%)$ mengalami perilaku temper tantrum dan hampir setengahnya $(27,8 \%)$ tidak mengalami perilaku temper tantrum.

Ibu yang bekerja maka waktu bersama anak akan berkurang, akan tetapi ibu harus mampu meluangkan waktu bersama dengan anak untuk membimbing, mengasuh, menjalin komunikasi, dan lain sebagainya. Hal ini sesuai dengan pernyataan Mangkuprawira dalam Imaniyah (2013) bahwa ibu bekerja mempunyai peran ganda, selain sebagai wanita karir juga sebagai ibu rumah tangga dimana ibu harus dapat membagi waktu antara pekerjaan dan mengasuh anak. Gunarsa (2008) dalam Imaniyah (2013) berpendapat bahwa ibu yang sibuk bekerja atau berkarir dapat mengakibatkan perhatian terhadap keluarga termasuk anak menjadi berkurang, bahkan tidak sedikit yang akhirnya tidak memperhatikan kondisi anak. Glick (2002) dalam Imaniyah (2013) menyatakan bahwa akibat ibu bekerja maka waktu kebersamaan dan quality time antara ibu dan anak akan berkurang, sehingga perkembangan mental dan kepribadian anak dapat terganggu, mereka lebih sering mengalami cemas akan, merasa diabaikan dan akan lebih cenderung mencari perhatian di luar rumah. Selain pada ibu 
bekerja hal ini juga dapat terjadi pada ibu yang tidak bekerja, ibu harus mampu membagi waktu untuk bisa bersama anak. Artinya tidak mutlak ibu yang berada di rumah (tidak bekerja) akan menjamin perkembangan anak sesuai dengan umurnya. Ibu yang tidak bekerja, yang memiliki banyak waktu, dimungkinkan pula perkembangan anaknya kurang baik. Hal ini terjadi karena secara fisik ibu berada dan bersama anak namun ibu tidak terlibat dalam proses stimulasi dengan anak. adanya cukup waktu berkualitas bersama anak dalam bermain dan melakukan stimulus yang adekuat pada anak baik pada ibu yang bekerja dan tidak bekerja menjadi salah satu penentu baik buruknya perkembangan anak.

Ibu yang tidak bekerja dan memiliki waktu kebersamaan yang lebih banyak belum tentu selalu lebih baik daripada ibu yang bekerja. hal ini dikarenakan kebanyakan waktu yang mereka miliki semata-mata untuk membersihkan dan mengurus rumah McIntosh dan Bauer (2006) dalam Imaniah (2013). Interaksi timbal balik antara anak dan orang tua akan menimbulkan timbal balik antara anak dengan orang tua dan akan menimbulkan keakraban dalam keluarga (Soejtiningsih, 2016). Interaksi tidak ditentukan seberapa lama orang tua bersama anaknya, tetapi lebih ditentukan seberapa lama orang tua bersama anak. Perhatian dari seorang ibu sangat penting untuk perkembangan emosional anak, ibu diharapkan memiliki waktu yang lebih banyak dengan anaknya sehingga ibu berperan sebagai pengasuh, pendidik, serta memberikan kasih sayang dengan baik dapat dilakukan dengan baik yaitu dengan memberikan waktu yang berkualitas terhadap perkembangan emosi anak-anaknya yang mengalami perilaku temper tantrum.

\section{PENUTUP}

\section{Kesimpulan}

1. Anak usia prasekolah di Bangkalan sebagian besar laki - laki sebanyak 57,1\%

2. Umur ibu sebagian besar 17-25 tahun sebanyak 54,3\%, sebagian besar ibu bekerja sebanyak $51,4 \%$.

3. Kejadian temper tantrum pada anak usia prasekolah di Bangkalan hampir seluruhnya mengalami sebanyak $85,7 \%$ anak.

4. Ada hubungan karakteristik anak dan ibu dengan kejadian temper tantrum pada anak usia prasekolah di Bangkalan.

\section{DAFTAR PUSTAKA}

Astuti, Yuni.(2016). Perilaku Tantrum Anak Usia 5-6 Tahun ditinjau dari Usia Menikah Orang Tua di Desa Bener, Kecamatan Kepil, Kabupaten Wonosobo. Skripsi Progam Studi Pendidikan Guru Pendidikan Anak Usia Dini, Fakultas Ilmu Pendidikan, Universitas Negeri Semarang.

Desiningrum, Dinie R.(2012) Buku ajar psikologi perkembangan 1.Semarang: Outline Buku Ajar

Dinantia, Fadila et al.(2014). Hubungan Pola Asuh Orang Tua dengan Frekuensi dan Intensitas Perilaku Temper Tantrum pada Anak Toddler di Kelurahan Suka Maju, Kecamatan Sail, Kota Pekanbaru. JOM PSIK Vol.1 No.2 Oktober 2014

Hidayat, Aziz, Alimul. 2011. Metode Penelitian Keperawatan dan Teknik Analisa Data. Jakarta : Salemba Medika

Hurlock, E. 2005. Perkembangan Anak Edisi Keenam Jilid I. Jakarta : Erlangga

Imaniyah, Dwi Miftah.(2013). Perbedaan Pencapain Perkembangan Anak Usia Prasekolah pada Ibu Bekerja dan Tidak Bekerja di Desa Serut Kecamatan Panti 
Kabupaten Jember. Skripsi Program Studi Sarjana Keperawatan Fakultas Keperawatan, Universitas Jember.

Kozier, B., et al.(2010). Fundamental Keperawatan.Jakarta: EGC.

Lusiana, Esti.(2015). Perbedaan Risiko Temper Tantrum Anak Usia Prasekolah Antara Ibu Bekerja dan Tidak Bekerja di Roudhotul Atfal MAN 2 Kelurahan Gebang Kecamatan Petrang Kabupaten Jember. Skripsi Program Studi Keperawatan Universitas Jember.

Nursalam. 2011. Konsep dan Penerapan Metodologi Penelitian Ilmu Keperawatan Pedoman Skripsi, Tesis, dan Instrumen Penelitian Keperawatan Edisi 2. Jakarta : Salemba Medika

Nursalam.(2013).Metodelogi Penelitian Ilmu Keperawatan.Jakarta: Salemba Medika.

Sanjaya, W. 2012. Strategi Pembelajaran Berorientasi Standart Proses Pendidikan. Jakarta : Kencana Prenada Media Group

Soetjiningsih.(2016). Tumbuh Kembang Anak.Edisi 2.Jakarta:EGC.

Sriyanti, Lilik.(2014). Psikologi Anak.Jawa Tengah: STAIN Salatiga Press.

Sunanti, Fitria et al. Karakteristik Orang Tua dan Perkembangan dengan Balita Usia 12-59 Bulan. Jurnal care vol.4, No.3, Tahun 2016.

Widyana, Erni Dwi. Pola Asuh Anak dan Pernikahan Usia Dini. Jurnal Pendidikan Kesehatan, Vol.4, No.1, April 2015 : 3339

Widyaninta, Albertin Melati. (2017). Pemahaman Ibu Mengenai Temper Tantrum Anak. Skripsi Program Studi Psikologi, Fakultas Psikologi, Universitas Sanata Dharma Yogyakarta.

Wiyouf,Rosa Maria Suwarni Yiw' et al. 2017. Hubungan Pola Komunikasi dengan Kejadian Temper Tantrum Pada Anak Usia Pra Sekolah Di TK Islamic Center Manado. e-Journal Keperawatan (e-Kp) Volume 5 Nomor 1, Februari 2017. 